Canadian Science Publishing

Canadian Journal of Physiology and Pharmacology Revue canadienne de physiologie et pharmacologie

\title{
Hepatoprotective activity of White Horehound (Marrubium vulgare) extract against Cyclophosphamide toxicity in male rats
}

\begin{tabular}{|r|l|}
\hline Journal: & Canadian Journal of Physiology and Pharmacology \\
\hline Manuscript ID & cjpp-2015-0405.R1 \\
\hline Danuscript Type: & Article \\
\hline Complete List of Authors: & $\begin{array}{l}\text { Ettaya, Amani; Laboratory of Animal Ecophysiology, Faculty of Science of } \\
\text { Sfax 3018 Sfax, Tunisia } \\
\text { Dhibi, Sabah; Laboratory of Animal Ecophysiology, Faculty of Science of } \\
\text { Sfax 3018 Sfax, Tunisia } \\
\text { Samout, Noura; Laboratory of Animal Ecophysiology, Faculty of Science of } \\
\text { Sfax 3018 Sfax, Tunisia } \\
\text { Elfeki, Abdelfattah; Laboratory of Animal Ecophysiology, Faculty of Science } \\
\text { of Sfax 3018 Sfax, Tunisia } \\
\text { Hfaiedh, Najla; Laboratory of Animal Ecophysiology, Faculty of Science of } \\
\text { Sfax 3018 Sfax, Tunisia }\end{array}$ \\
\hline Keyword: & \begin{tabular}{l} 
Cyclophosphamide, Marrubium vulgare, Oxidative stress, Liver \\
\hline
\end{tabular} \\
\hline \multicolumn{2}{|c}{} \\
\hline
\end{tabular}

\section{SCHOLARONE"}

Manuscripts 


\section{Hepatoprotective activity of White Horehound (Marrubium vulgare) extract against Cyclophosphamide toxicity in male rats}

Ettaya, Amani; Dhibi, Sabah; Samout, Noura; Elfeki, Abdelfettah; Hfaiedh, Najla

Laboratory of Animal Ecophysiology, Faculty of Science of Sfax 3018 Sfax, Tunisia

Laboratory of Animal Ecophysiology, Faculty of Science of Gafsa 2100 Gafsa, Tunisia

Corresponding author: Amani Ettaya

Tel: 0021654005960

Fax: 0021676211026

E-mail address: najhfaiedh@yahoo.fr

Mme Najla Hfaiedh

Associate Professor in Animal Physiology

Department of Life Sciences, Faculty of Sciences of Gafsa

Campus Universitaire; Sidi Ahmed Zarrouk, Gafsa, 2112, Tunisia

Tel: +21697012512

Fax: +21676211026 


\section{Abstract}

The hepatoprotective activity of Marrubium vulgare against cyclophosphamide toxicity in Wistar rats was evaluated. Adult male rats were divided into 4 groups of six each: a control group, a group injected with cyclophosphamide $(150 \mathrm{mg} / \mathrm{kg})$ for 3 days, a group orally given a Marrubium vulgare aqueous extract (500 $\mathrm{mg}$ of dry leaves $/ \mathrm{kg} /$ day) for 30 days then treated with cyclophosphamide, and a group receiving only Marrubium vulgare for 30 days. After 33 days of treatment, activities of alanine amino transferase (ALAT), aspartate amino transferase (ASAT), lactate dehydrogenase (LDH) and alkaline phosphatase (ALP) were determined in serum. Moreover, lipid peroxidation level and superoxide dismutase (SOD) activities, catalase (CAT) and glutathione peroxidase (GPx) were measured in liver. Alterations of these hepatic biomarkers and increased lipid peroxidation confirmed cyclophosphamide-induced liver toxicity. Cyclophosphamide also decreased the enzymatic defense system against oxidative stress. However, when this drug was administered in rats given Marrubium vulgare extract, all the biological parameters underwent much less alteration. Administration of Marrubium vulgare extract was found to be beneficial by attenuating cyclophosphamide-induced liver damage. The protective effect of the plant is mainly attributed to its antioxidant properties and the existence of phenolic acids and flavonoids, as highlighted by HPLC-based analysis.

Keywords: Cyclophosphamide,Marrubium vulgare,Oxidative stress,Liver 


\section{Introduction}

Cyclophosphamide (CP) is an antineoplastic agent from the oxazophorines group. It has been proven to be effective against some auto-immune diseases and a variety of cancer types such as lymphomas, neuroblastomas, breast cancer, ovary adenocarcinoma, myeloma and chronic lymphocyticleukemia (Baumann and Preiss 2001). During clinical application, it is important to prevent or reduce CP-induced DNA damage (Tripathi and Jena 2008). Notwithstanding the fact that it acts as an efficient chemotherapeutic mediator, CP intake is associated with several significant adverse effects such as mutagenicity, carcinogenicity, immunosuppression, cardiac toxicity, and lung and kidney toxicity leading to the formation of reactive oxygen species as well as lipid peroxidation (Stankiewicz et al. 2002). Previous studies have shown that therapeutic doses of CP could be toxic to liver (Snover et al. 1989; Sulkowska et al. 2002). CP is metabolized via the hepatic P450 enzymatic system resulting in the formation of 4hydroxycyclophosphamide and its tautomer aldocyclophosphamide which induce an oxidative stress by producing hydroxyl radicals and altering the antioxidant status of a cell (Selvakumar et al. 2005). Other findings suggest that CP depresses antioxidant defense in liver while its metabolism generates superoxide anions and hydrogen peroxide $\left(\mathrm{H}_{2} \mathrm{O}_{2}\right)$ (Singh et al. 2014). Additionally, Tripathi et al. (2010) point out that CP, administered to mice at a dose of 100 and $200 \mathrm{mg} / \mathrm{kg}$, i.p., induces DNA damage in both bone marrow cells and peripheral blood lymphocyte cells. Injection of CP into rats also results in a repression of GPx as well as SOD activities and, on the other hand, an increase in TBARS content in blood. The oxidative stress emerging from excessive generation of reactive oxygen species as well as flawed antioxidant defense system may account for many side effects of CP treatment.

Several experimental studies have sought to prevent troublesome side effects caused by drugs. Treatment materials used for this purpose include herbal medicine as an ancient discipline relying on herbal remedies or plant extracts. 
M. vulgare L. (Lamiaceae) naturally grows as a native plant in Northern and Southern USA and is also found in the Mediterranean area (Tunisia, Alegria, etc) as well as Western Asia as far as India. This plant is used in various traditional medical applications and is characterized by anti-diabetic, anti-oxidant and antibacterial properties (Boudjelal et al. 2012; Ghedadba et al. 2014; Mubashir et al. 2008). It is also claimed to induce gastroprotective (De Oliveira et al. 2011) and anti-inflammatory (Kanyonga et al. 2011) activities. Phytochemically, M. vulgare is characterized by the presence of a variety of compounds such as polyphenols, tannins, flavonoids, diterpenes and saponins (Bouterfas et al. 2013; El Bardai et al. 2003; Kurbatova et al. 2003). The extract of $M$. vulgare has been proven to have hepatoprotective effects in rats (Akther et al. 2013; Elberry et al. 2010). The antioxidant properties of M. vulgare extract have been confirmed by its ability to trap reactive oxygen species (ROS), inhibit lipid peroxidation and enhance the efficiency of endogenous antioxidant systems (Akther et al. 2013).

This work aimed to investigate the hepatoprotective effect of M. vulgare on CP-induced toxic damage to rats. In the first part of this study, some biochemical parameters (i.e. alanine aminotransferase (ALAT), lactate dehydrogenase (LDH), aspartate aminotransferase (ASAT) and alkalinephosphatase (ALP) activities) were measured in blood serum. In addition, lipid peroxidation level and antioxidant enzyme (SOD, GPx, and CAT) activities were determined in liver. In the second part, a phytochemical study of the M. vulgare extract was carried out to identify some antioxidant substances.

\section{Materials and methods}

\section{Chemicals}

Cyclophosphamide (Endoxan) was obtained as a powder from the pharmacy of the Regional Hospital of Gafsa, Tunisia, to be dissolved in saline for injection. The CP dose used in the present study was derived from previous reports (Senthilkumar et al. 2005) and determined on the basis of some preliminary experiments. 


\section{Preparation of the M. vulgare extract}

Samples of M. vulgare were collected in November 2013 from the Gafsa area located in south-west Tunisia. They were identified by a botanist at Faculty of Sciences of Gafsa, Tunisia. The plant leaves were washed, dried at a room temperature in the dark then ground.1g of the obtained dry powder was added to $100 \mathrm{ml}$ of boiling distilled water. After reaching room temperature (ca. $15 \mathrm{~min}$ ), the prepared infusion was filtered in order to carry out biological tests on the experimental animals.

\section{Experimental design}

Rats were divided into 4 groups of 6 each: (1) a control group (C); (2) a group of rats fed with CP by intraperitoneal injection $(150 \mathrm{mg} / \mathrm{kg})$ for 3 successive days, following the protocol of Senthilkumar et al. (2005) (CP); (3) a group of rats pre-treated with M. vulgare extract at a dose corresponding to $500 \mathrm{mg}$ of dry leaves powder/kg body weight per day given by oral gavage for 30 successive days (Elberry et al. 2010), then the rats were injected with CP (CPM); and (4) a group of rats receiving M. vulgare extract for only 30 successive days (M). After 33 days, all the animals were quickly sacrificed via decapitation in order to minimize the treatment stress. Blood serum was obtained by centrifugation $\left(1500 \times \mathrm{g}, 15 \mathrm{~min}, 4^{\circ} \mathrm{C}\right)$ and the livers were removed, cleaned of fat and weighed. All samples were stored at $-80^{\circ} \mathrm{C}$ until use. All the experimental procedures were conducted in compliance with Guidelines on the Use of Living Animals in Scientific Investigations.

\section{Biochemical assays}

Based on Yagi's (1976) method, lipid peroxidation level was measured by the quantity of thiobarbituric acid reactive substances (TBARS). The test involved combination of $125 \mu 1$ of supernatant (S1 ) and $175 \mu$ l of 20\% trichloroacetic acid containing 1\% butyl-hydroxytoluene and centrifuged $\left(1000 \times \mathrm{g}, 10 \mathrm{~min}, 4^{\circ} \mathrm{C}\right)$. Then, $200 \mu \mathrm{l}$ of supernatant (S2) was mixed with 40 $\mu \mathrm{l}$ of $\mathrm{HCl}(0.6 \mathrm{M})$ and $160 \mu \mathrm{l}$ of thiobarbituric acid $(0.72 \mathrm{mM})$. The mixture was heated at 
$80^{\circ} \mathrm{C}$ for $10 \mathrm{~min}$ and the absorbance was measured at $530 \mathrm{~nm}$. The total TBARS amount was calculated using an extinction coefficient of $156 \mathrm{mM}-1 \cdot \mathrm{cm}^{-1}$ and expressed in nmoles $/ \mathrm{mg}$ protein.

Catalase (CAT) activity was measured by the method described by Aebi (1984). The reaction mixture $(1 \mathrm{ml})$ consisted of $100 \mathrm{mM}$ phosphate buffer at a $\mathrm{pH}$ of 7, $100 \mathrm{mM} \mathrm{H}_{2} \mathrm{O}_{2}$ and $20 \mu \mathrm{l}$ (about $1-1.5 \mathrm{mg}$ of protein) of liver homogenate. In order to track the decomposition of $\mathrm{H}_{2} \mathrm{O}_{2}$ at $25^{\circ} \mathrm{C}$, the decrease in absorbance was measured at $240 \mathrm{~nm}$ for 1 min. Enzyme activity was determined by means of an extinction coefficient of 0.043 $\mathrm{mM}-1 \cdot \mathrm{cm}-1$ and expressed in $\mu \mathrm{M} \mathrm{H} 2 \mathrm{O} 2$ destroyed $\mathrm{min} / \mathrm{mg}$ protein.

The total superoxide-dismutase (SOD) activity was determined by measuring its capacity to exert inhibitory effect on the photoreduction of nitrobluetetrazolium (NBT) (Sun et al. 1988). One unit of SOD represents inhibition of NBT photoreduction by $50 \%$, and the activity was expressed as units $/ \mathrm{mg}$ protein, at $25^{\circ} \mathrm{C}$.

Glutathione-peroxidase (GPx) activity was assayed using the method described by Flohe and Gunzler 1984) at $25^{\circ} \mathrm{C}$ and expressed as $\mu$ moles of GSH oxidized $/ \mathrm{min} / \mathrm{g}$ protein.

Protein content in tissue extracts was determined using Lowry et al's method (1951) and thus bovine serum albumine as a standard.

The serum activities of alkaline phosphatase (ALP), lactate dehydrogenase (LDH), aspartate amino transferase (ASAT) and alanine amino transferase (ALAT) were identified using kit methods (Spinreact).

\section{Assay of Free Radical-Scavenging Activity on DPPH}

The Assay of Free Radical-Scavenging Activity of M. vulgare was measured using the stable radical DPPH according to Grzegorczyk et al.'s (2007) protocol. An aqueous solution of $M$. vulgare $(1 \mathrm{ml})$ at various concentrations $(50-400 \mu \mathrm{g} / \mathrm{ml})$ was added to $1 \mathrm{ml}$ of a 0.1 
methanolic solution of DPPH and kept at $27^{\circ} \mathrm{C}$ for $30 \mathrm{~min}$. This was followed by reading the absorbance at $517 \mathrm{~nm}$.

DPPH radical-scavenging activity (RSA), expressed as a percentage, was calculated using the following formula:

$$
\mathrm{RSA} \%=\mathrm{ADPPH}-(\text { Asample }- \text { Acontrol }) \times 100 / \mathrm{ADPPH} .
$$

Ferric reducing antioxidant power (FRAP) of Marrubium vulgare extract

The FRAP of $M$. vulgare extract was determined in accordance with the protocol described in Chu et al. (2000). $2.5 \mathrm{ml}$ of Potassium phosphate buffer (0.1 M, pH 6.6) as well as $2.5 \mathrm{ml}$ of $1 \%(\mathrm{w} / \mathrm{v})$ potassium ferricyanide were combined with $1.0 \mathrm{ml}$ of $M$. vulgare extract solution at various concentrations $(50-500 \mu \mathrm{g} / \mathrm{ml})$. The reaction was incubated at $50 \circ \mathrm{C}$ for $20 \mathrm{~min}$, then $2.5 \mathrm{ml}$ of $10 \%(\mathrm{w} / \mathrm{v})$ trichloroacetic acid was added. After that, water $(2.5 \mathrm{ml})$ and $0.5 \mathrm{ml}$ of $0.1 \%(\mathrm{w} / \mathrm{v}) \mathrm{FeCl} 3$ was added to $2.5 \mathrm{ml}$ of the reaction mixture and incubated at $28{ }^{\circ} \mathrm{C}$ for 30 min to facilitate color change. The absorbance was measured at $700 \mathrm{~nm}$ as a function of $M$. vulgare extract concentration $(\mu \mathrm{g} / \mathrm{ml})$ and compared with ascorbic acid (AA) used as a standards.

\section{Extraction of M. vulgare Phenolic Acids and Flavonoids}

The dried powder of M. vulgare $(1 \mathrm{~g})$ was mixed with $10 \mathrm{ml}$ of extraction solution (methanol $80 \%$, agitated for $10 \mathrm{~min}$, and then centrifuged at $12,000 \times \mathrm{g}$ for $5 \mathrm{~min}$. A $0.5 \mathrm{ml}$ aliquot of supernatant was added to $0.5 \mathrm{ml}$ of acetone and agitated. After that, the homogenate was centrifuged $(12,000 \times \mathrm{g}$ for $5 \mathrm{~min})$. A Speed Vac device was used to dry the homogenate to be used for HPLC analysis of phenolic acids and flavonoids (Hfaiedh et al. 2013). 


\section{HPLC Analysis Conditions}

Examination by liquid chromatography was carried out using A Varian Prostar HPLC system equipped with a ProStar 230 ternary pump, a manual injector and a ProStar 330 diode array detector. HPLC separation of the active compounds was conveyed on a $5 \mu \mathrm{m}$ particle $\mathrm{C}-18$ reversed-phase column (Varian, $150 \times 4.6 \mathrm{~mm}$ ). The mobile phase was composed of solvent A: water and acetic acid $(98: 2 \mathrm{v} / \mathrm{v})$, and solvent B: water, acetonitrile and acetic acid (58:40:2 $\mathrm{v} / \mathrm{v})$. The gradient elution used was: $0-80 \% \mathrm{~B}$ for $55 \mathrm{~min}, 80-100 \% \mathrm{~B}$ for $15 \mathrm{~min}$ and $100-0 \%$ B for $5 \mathrm{~min}$. The flow rate amounted to $0.9 \mathrm{ml} / \mathrm{min}$ with an injection volume of $20 \mu \mathrm{l}$. Compound identification was carried out at $280 \mathrm{~nm}$ for phenolic acids and at $360 \mathrm{~nm}$ for flavonoids on the basis of a comparison between the retention time as well as mass spectra of the peaks in the injected extracts and those of HPLC standard compounds.

\section{Results}

\section{Effects of treatments on plasma biochemical parameters}

Treatment with CP resulted in a significant increase in ASAT, ALAT, LDH and ALP activities compared with the control (Table 1). In the case of CP-treated rats receiving $M$. vulgare, all the aforementioned biomarkers reverted to almost normal values.

\section{Oxidative damage}

CP significantly increased the hepatic TBARS concentration compared to controls (Fig.1). Administration of M. vulgare extract led to a reduction in the TBARS levels.

\section{Antioxidant activities}

The exposure of rats to $\mathrm{CP}$ induced significant adverse effects on the liver redox status; SOD, CAT and GPx markedly decreased compared to controls (fig.1). However, when the animals received $M$. vulgare extract, the antioxidant enzymatic defense system was significantly corrected. 


\section{DPPH radical scavenging activity}

As shown in Fig. 2, free radical scavenging activities of $M$. vulgare extract were measured by DPPH assay. It is clear from Fig. 2 that the anti-DPPH activity increased with increasing $M$. vulgare concentration until a maximum concentration $(400 \mu \mathrm{g} / \mathrm{ml})$ was reached.

Based on the curve presented in Fig. 2, effective concentration (EC50) of M. vulgare extract, which gave $50 \%$ inhibition of the DPPH radical, was found to be $180 \pm 2.54 \mu \mathrm{g} / \mathrm{ml}$. This indicated that the anti-DPPH activity was relatively lower than that of ascorbic acid $110 \pm$

\section{$4.12 \mu \mathrm{g} / \mathrm{ml}$.}

FRAP test

As can be clearly seen in Fig. 3, M. vulgare extract was capable of reducing $\mathrm{Fe}^{3+}$ to $\mathrm{Fe}^{2+}$ at different concentration ranges. The reducing power of this plant increased with increasing concentrations and was able to serve as an electron donor. The reducing power of M. vulgare extract at $500 \mu \mathrm{g} / \mathrm{ml}$ was found to be $0.37 \pm 0.021$ and thus significantly lower than that of ascorbic acid, which was used as positive control (1.02 \pm 0.04$)$, at the same concentration.

\section{HPLC analysis of marrubium extracts phenolic acids and flavonoids}

The HPLC-based analysis of M. vulgare extract indicated the presence of phenolic acids and flavonoids. As shown in Fig. 4, this plant contained 32 unknown compounds and six known phenolic acids: Gallic, Catechic, Caffeic , Epicatechic, Vanillic and Coummarin acids, with a retention time of $7.179 \mathrm{~min}, 15.144 \mathrm{~min}, 17.285 \mathrm{~min}, 18.387 \mathrm{~min}, 21.131 \mathrm{~min}$ and 27.096 min, respectively. The HPLC elution profile of flavonoids displayed in Fig. 5 revealed 36 compounds absorbed at $360 \mathrm{~nm}$ including three known flavonoids; Rutin, Quercetin and Kaempferol, with retention time of $20.717 \mathrm{~min}, 29.883 \mathrm{~min}$ and $33.019 \mathrm{~min}$, respectively. Thus, M. vulgare proved to be rich in antioxidant compounds (i.e. phenolic acids and flavonoids) which enabled it to have a protective effect on toxicity. 


\section{Discussion}

$\mathrm{CP}$ is an alkylating agent widely used in chemotherapy to slow or prevent cell proliferation. $\mathrm{CP}$ is converted by the liver oxidase system mixed function into two metabolites: phosphoramide mustard and acrolein. Phosphoramide mustard is responsible for therapeutic activity, and metabolite acrolein induces inactivation of microsomal enzymes resulting in increased reactive oxygen species (ROS) generation as well as lipid peroxidation (Kehrer and Biswal 2000). In our study, CP injection at a dose of $150 \mathrm{mg} / \mathrm{kg}$ caused oxidative stress exhibited by an increase in lipid peroxidation level as well as weakening of the antioxidative status in the hepatic tissue of rats. The obtained results are in agreement with those reported in other works suggesting that $\mathrm{CP}$ administration induces a significant increase in TABRS level in liver (Lata et al. 2014; Manda and Bhatia 2003). An increase in TBARS level may alter the cellular membrane structure and then block cellular metabolism. These factors may explain the negative effects of $\mathrm{CP}$ on hepatocytes. CP-induced hepatotoxicity can also be explained by mitochondrial membrane potential alteration caused by acrolein in hepatocytes (Lindley et al. 2002; Luo et al. 2005; Pass et al. 2005). The same metabolite induces necrosis and apoptosis in hepatic tissue as reported by Cuce et al. 2015. In fact, in liver, hepatocytes are essentially affected by ROS and oxidative stress, which could result in apoptosis and necrosis and is an explanatory factor that could account for hepatotoxicity. Indeed, the release of cytochrome c from damaged mitochondria during oxidative stress induced caspase cascade. During cellular apoptosis, chromatin condensation as well as DNA fragmentaion occur without damaging the plasma membrane. An alteration in signalling pathways regulates apoptosis and thus prevents its occurrence (Kang and Reynolds 2009). There are various factors involved in the regulation of apoptosis such as Bcl-2. In fact, Bcl-2-family proteins are critical regulators of apoptosis, and their primary site of action is on the outer mitochondrial membrane (Lindsay et al. 2011). Once liver cells were damaged by oxidative stress, 
mitochondrial membranes were impaired, which resulted in almost complete inhibition of the antiapoptotic effect of Bcl-2 described by Schwartz and Waxman (2001).

$\mathrm{CP}$ administration was found to induce disturbances of the antioxidant system indicated by changes observed in enzymatic antioxidant parameters. CP injection reduced superoxide dismutase, CAT and glutathione peroxydase activities in liver. It's known that the activities of SOD and GPx behave in two different ways face to oxidative stress; an overexpression of the enzyme in a first stage and then their inhibition if the stress is permanent. It was noted that $\mathrm{CP}$ metabolized by cytochrome P450 induced an excessive generation of free radicals (Olayinka et al. 2015), which may explain the severe alteration of antioxidant enzyme status in the liver. In fact, $\mathrm{CP}$ metabolism produced highly reactive electrophiles accompanied by attenuation of GSH in CP-treated group that can be associated with the electrophilic burden on the cells and the formation of acrolein. The results found in this study are similar to those of Haque et al. (2001); Rajasekaran et al. (2002); Selvakumar et al. (2005); Shanmugarajan et al. (2008) who point out that SOD, CAT and GPx play a critical role in the fight against free radicals and their elimination which explains the decrease in the activity of the three enzymes after the CP administration that induced hepatotoxicity. However, in the case of rats pre-treated with $M$. vulgare, the perturbation was significantly attenuated, which was indicated by reduction in lipid peroxidation level and enhancement of antioxidant states (SOD, GPx and CAT) when compared with those of normal rats, as suggested by Akther et al. (2013), Haque et al. (2003) as well as Zarei and Shivanandappa (2013). This beneficial effect can be explained by the modulation of the cellular GSH pool which was found to improve the antioxidant and free radical-scavenging activity. It is also suggested that the components of $M$. vulgare appeared to have protective effect against $\mathrm{CP}$-generated aggressive oxidants.

The protective effect of $M$. vulgare can be attributed to the presence of phenolic acids and flavonoids as revealed by the HPLC analysis. In fact, phenolic acids and flavonoids were able 
to release a hydrogen proton from their hydroxyl group, trap free radicals and prevent $\mathrm{CP}$ induced liver damage

Based on the HPLC analysis of M.vulgare extract, phenolic acids (acid Gallic, Catechin, Caffeic, Epicatechin, Vanillic and Coummarin) and flavonoids (Rutin, Quercetin and Kampferol) were identified. Similar findings have been reported by Boudjelal et al. (2012) and Pukalskas et al. (2012), emphasizing that M. vulgare is an influential factor to counteract the oxidative stress-induced liver damage.

Another indicator of CP-induced hepatic toxicity was perturbation of biochemical parameters (ASAT, ALAT, LDH and ALP) which are markers of hepatic damage. In the present study, damaged of hepatocytes can been associated to the increase activities of ASAT, ALAT, LDH and ALP in serum after injection by CP for 3 successive days which is in agreement with previous reports indicating that these biochemical markers increases during membrane hepatocytes damage (Alabbassi 2010; Habibi et al.2014; Shokrzadeh et al.2006). Based on the experiments performed in this study, $M$. vulgare extract was found to be beneficial in reducing the pathological shifts of all the biochemical parameters studied. The reduction of these parameters is mainly due to the presence of antioxidant properties capable of scavenging free radicals and protecting cellular structures against cytotoxic effects as shown by the DPPH, Ferric reducing power (FRAP). Results reported by several researchers (e.g. Ghedadba et al. 2014; Kadri et al. 2011) are in agreement with the findings obtained in the present study which emphasizes the alleviating effect of $M$. vulgare on liver damage (Elberry et al. 2010; Mubashir el al. 2009).

\section{Conclusion}

In this study, it was found that aqueous extract of $M$. vulgare possesses protective activity against CP-induced hepatotoxicity and oxidative stress. This efficiency is mainly attributed to antioxidant properties as well as the presence of phenolic acids and flavonoids in this plant. 


\section{Acknowledgments}

This work was funded by the Tunisian Ministry of Higher Education and Scientific Research through Integrated Physiology Laboratory in Faculty of Sciences of Sfax, Tunisia. We greatly appreciate the technical support provided by l'Unité des Services Communs in Faculty of Sciences of Gafsa, Tunisia. We also would like to express our special thanks to Mr Zied Tlili, a teacher of English for Specific Purposes, for his diligent editing of an earlier version of this paper.

\section{Conflict of interest:}

The authors declare that there is no conflict of interest.

\section{References}

Aebi, H.1984. Catalase in Vitro. Methods Enzymol. 105: 121-126.

Akther,N., Shawl, A. S., Sultana, S., Chandan, B. K., Akhter, M. 2013. Hepatoprotective activity of Marrubium vulgare against paracetamol induced toxicity. J .Pharm. Res. 7:565570.

Alabbassi, M.G.2010. Melatonin Ameliorates Hepatic Damage Induced by Cyclophosphamide in Rats.Al-Taqani. 23: 1-7.

Baumann,F., and Preiss, R.2001. Cyclophosphamide and related anticancer drugs. J. Chromatogr .B. 764:173-192.

Boudjelal,A., Henchiri, C., Siracusa, L., Sari, M., Ruberto, G.2012.Compositional analysis and in vivo anti-diabetic activity of wild Algerian Marrubium vulgare L. infusion.Fitoterapia. $83: 286-292$

Bouterfas, K., Mehdadi, Z., Latreche, A., Zouaoui, H.,Bouredja,N. 2013.Quantification of some polyphenols of Marrubium vulgareL. of Tessala mount (western Algeria) at the vegetative and the flowering periods .Les Technologies De Laboratoire. 8:34-41. 
Chu, Y. H.,Chang,C. L., Hsu, H. F. 2000.Flavonoid content of several vegetables and their antioxidant activity. J. Sci. Food. Agric. 80:561-566.

Cuce,G.,Cetinkaya,S., Koc, T.,Esen, H.H., Limandal,C., et al.2015. Chemoprotective effect of vitamin $\mathrm{E}$ in cyclophosphamide-induced hepatotoxicity in rats.Chem. Biol. Interact. 232: 711.

De Oliveira, A.P., Santin, J.R., Lemos, M., Júnior, L.C.K.,Couto, A. G., et al. 2011. Gastroprotective activity of methanol extract and marrubiin obtained from leaves of Marrubium vulgareL. (Lamiaceae). J. Pharma. Pharmacol. 63:1230-1237.

ElBardai, S., Morel, N.,Wibo, M., Fabre, N.,Llabres, G., et al . 2003. The vasorelaxant activity of marrubenol and marrubiin from Marrubium vulgare. Planta Med. 69:75-77.

Elberry, A. A., Harraz, F.M., Ghareib, S., Nagy, A. A., Gabr, S.A., et al. 2010.Antihepatotoxic Effect of MarrubiumVulgare and Withania Somnifera Extracts on Carbon Tetrachloride-induced hepatotoxicity in rats.J. Basic. Clin.Pharm.001:247-254.

Flohe, L., and Gunzler, W. A.1984. Assays of Glutathione Peroxidase.Methods Enzymol. 105:114-121.

Ghedadba, N., Bousselsela, H., Hambaba, L., Benbia, S., Mouloud, Y. 2014. Évaluation de l'activité antioxydante et antimicrobienne des feuilles et des sommités fleuries de Marrubium vulgare L. Phytothérapie.12 :15-24.

Grzegorczyk, I., Matkowski, A.,Wysokinska, H.2007. An- tioxidant Activity of Extracts from in Vitro Cultures of Salvia officinalisL.Food Chem. 104: 536-541.

Habibi, E., Shokrzadeh, M.,Chabra, A., Naghshvar, F., Maleki, R. K., et al. 2014. Protective effects of Origanum vulgare ethanol extract against cyclophosphamide-induced liver toxicity in mice.Pharm. Biol. 53: 1-6. 
Haque, R., Bin-Hafeez,B., Ahmad, I., Parvez, S., Pandey, S., et al. 2001. Protective effects of Emblica officinalis Gaertn. in cyclophosphamide-treated mice.Hum. Exp. Toxicol.20:643650.

Haque, R., Bin-Hafeez, B.,Parvez, S., Pandey, S., Sayeed, I., et al. 2003. Aqueous extract of walnut (Juglans regiaL.) protects mice against cyclophosphamide induced biochemical toxicity.Hum. Exp. Toxicol.22:473-480.

Hfaiedh, N., Mbarki, S., Alimi, H., Murat, J. C.,Elfeki, A. 2013. Diabetes-Induced Damages in Rat Kidney and Brain and Protective Effects of Natural Antioxidants. Food Nutr. Sci. 4 : 436-444.

Kadri, A., Zarai, Z., Békir, A., Gharsallah, N., Damak, M., et al. 2011. Chemical composition and antioxidant activity of Marrubium vulgareL. essential oil from Tunisia.Afr. J. Biotechnol. 10: $3908-3914$.

Kang,M. H., and Reynolds, C. P. 2009. Bcl-2 Inhibitors:TargetingMitochondrial Apoptotic Pathways in Cancer Therapy. Clin. Cancer Res. 15 :1126-1132.

Kehrer, J. P.,and Biswal, S. S. 2000.The Molecular effect of Arceolin. Toxicol. Sci. 57: 6-15

Kanyonga, P. M., Faouzi, M. A., Meddah, B., Mpona, M., Essassi,E.M., et al.2011. Assessment of methanolic extract of Marrubium vulgare for antiinflammatory, analgesic and anti-microbiologic activities.J. Chem. Pharm. Res. 3: 199-204.

Kurbatova, N.V.,Muzychkina, R. A.,Mukhitdinov, N. M., Parshina, G. N. 2003.Comparative phytochemical investigation of the composition and content of biologically active substances in Marrubium vulgare and Marrubium alternidens. Chem. Nat. Comp. 39: 501-502.

Lata,S., Singh, S., NathTiwari, K., Upadhyay, R. 2014. Evaluation of the Antioxidant and Hepatoprotective Effect of Phyllanthus fraternus Against a Chemotherapeutic Drug Cyclophosphamide.Appl. Biochem. Biotechnol. 173: 2163-2173. 
Lear, L., Nation, R. L., Stupans, I. 1992. Effects of cyclophosphamide and adriamycin on rat hepatic microsomal glucuronidation and lipid peroxidation.Biochem. Pharmacol. 44:747-753. Lindley, C. M, Hamilton, G., McCune, J .S, Faucette,S.,Shord,S.S., et al. 2002. The effect of cyclophosphamide with and without dexamethasone on cytochrome P450 3A4 and 2B6 in human hepatocytes.Drug Metab. Dispos. 30: 814-821.

Lindsay, J., Esposti, M. D., Gilmore, A. P. 2011. Bcl-2 proteins and mitochondria-Specificity in membrane targeting for death. Biochim. Biophys. Acta. 1813 :532-539.

Lowry, O. H., Rosebrough, N. J., Farr, A.L., Randall, R.J. 1951. Protein measurement with the Folin phenol reagent. J. Biol. Chem. 193:265-275.

Luo, J., Robinson, J.P., Shi, R. 2005. Acrolein-induced cell death in PC12 cells: role of mitochondria-mediated oxidative stress. Neurochem. Int. 47:449-457.

Manda, K., and Bhatia,A. L.2003. Prophylactic action of melatonin againstcyclophosphamide-induced oxidative stress in mice.Cell Biol. Toxicol. 19: 367-372.

Mubashir, H.M., Bahar, A., Suroor, A. K.,Shah, M. Y., Shamshir, K. 2009. Antihepatotoxic activity of aqueous extract of Marrubium vulgare whole plant in $\mathrm{CCl}_{4}$ induced toxicity. Indian J. Nat.Prod. 25: 3-8.

Mubashir, H.M., Bahar, A., Zargar, I., Khan, S. A., Khan, S., et al.2008. Antibacterial activity of whole plant extract of Marrubium vulgare.Afr.J. Biotechnol. 7: 086-087.

Olayinka, O. T., Ore, A., Ola, O. S., Adeyemo, O.A. 2015. Ameliorative Effect of Gallic Acid on Cyclophosphamide-Induced Oxidative Injury and Hepatic Dysfunction in Rats. Med. Sci. $3: 78-92$.

Pass, G. J., Carrie, D.,Boylan, M.,Sally, L., Ericet, W., al. 2005. Role of Hepatic Cytochrome P450s in the Pharmacokinetics and Toxicity of Cyclophosphamide: Studies with the Hepatic Cytochrome P450 Reductase Null Mouse.Cancer Res. 65: 4211-4217. 
Pukalskas, A., Venskutonis, P. R., Salido, S., De Waard, P., van Beek, T. A. 2012. Isolation, identification and activity of natural antioxidants from horehound (Marrubium vulgareL.) cultivated in Lithuania. Food Chem.130: 695-701.

Rajasekaran, N.S., Devaraj,H., Devaraj, S.N. 2002. The effect of glutathione monoester (GME) on glutathione (GSH) depleted rat liver. J. Nutr. Biochem. 13: 302-306.

Schwartz, P. S., and Waxman, D. J. 2001. Cyclophosphamide Induces Caspase 9-Dependent Apoptosis in 9L Tumor Cells. Mol. Pharmacol. 60 :1268-1279.

Selvakumar, E., Prahalathan, C., Mythili, Y., Varalakshmi, T. 2005.Mitigation of oxidative stress in cyclophosphamide-challenged hepatic tissue by DL- $\alpha$-lipoicacid.Mol.Cell Biochem. 272:179-185.

Senthilkumar, S., Devaki, T., Manohar, B. M., Babu, M. S. 2006. Effect of squalene on cyclophosphamide-induced toxicity. Clin. Chim. Acta. 364: 335-342.

Shanmugarajan,T.S., Arunsundar, A., Somasundaram, I., Sivaraman, D. 2008. Ameliorative Effect of Ficus hispida Linn.Leaf Extract on Cyclophosphamide-Induced Oxidative Hepatic Injury in Rats.J. Pharmacol. Toxicol. 3: 363-372.

Shokrzadeh,M., Ahmadi, A., Naghshvar, F., Chabra, A., Jafarinejhad, M. 2014. Prophylactic Efficacy of Melatonin on Cyclophosphamide-Induced Liver Toxicity in Mice.BioMed Res. Int. 2014: 470-425.

Singh, S., Lata, S., Tiwari, K. N. 2014. Aegle marmelos leaves protect Liver against Toxic effects of Cyclophosphamide in mice. N. Y. Sci. J .7:43-53.

Snover DC, Weisdorf S, Bloomer J, Mc Glave P, Weisdorf D . 1989. Nodularregenerative hyperplasia of the liver following bone marrow transplantation. Hepatology. 9: 443-448.

Stankiewicz, A., Skrzydlewska, E., Makieła,M. 2002. Effects of amifostine on liver oxidative stress caused by cyclophosphamide administration to rats.Drug Metabol. Drug Interact. $19: 67-82$. 
Sulkowska, M., Skrzydlewska, E., Sobaniec-Łotowska, M., Famulski,W.,Terlikowsk,S., et al. 2002. Effect of cyclophosphamide-induced generation reactive oxygen formson ultrastructure of the liver and lung.Bull. Vet. Inst. Pulawy. 46: 239-246.

Sun, Y., Oberley, L. W., Li, Y.1988. A Simple Method for Clinical Assay of Superoxide Dismutase.Clin. Chem. 34:497-500.

Tripathi, D. N., and Jena, J. B.2008. Astaxanthin inhibits cytotoxic and genotoxic effects of cyclophosphamide in mice germ cells. Toxicology. 248: 96-103.

Tripathi,P., Tripathi, R., Patel, R.K.2010. Investigation of Antimutagenic Potential of Embelia Ribes Fruit Extract Against Genotoxicity and Oxidative Stress Induced by Cyclophosphamide. Pharmacologyonline. 3: 867-885.

Yagi, K. A. 1976. Simple Fluorometric Assay for Lipoperoxide in Blood Plasma.Biochem. Med. 15: 212-216.

Zarei, M., and Shivanandappa,T. 2013. Amelioration of cyclophosphamide-induced hepatotoxicity by by the rootextract of Decalepis hamiltonii in mice. Food Chem. Toxicol. 57:179-184. 
Table 1. Blood ALAT (UI/L), ASAT (UI/L), ALP (UI/L) and LDH (UI/L) levels after 33 days of treatment in: controls (C), Cyclophosphamide-treated rats (CP), M.vulgare treated rats (M) and Cyclophosphamide treated rats with M.vulgare (CPM). Values are the mean of 6 measurements $\pm \mathrm{SD} . * * p \leq 0.01$, as compared to control group $(\mathrm{C}) .++p \leq 0.01$, as compared to treated group $(\mathrm{CP})$.

\begin{tabular}{|l|l|l|l|l|}
\hline Group & \multicolumn{1}{|c|}{ C } & \multicolumn{1}{|c|}{ CP } & CPM & M \\
\hline ALP & $35.22 \pm 0.80$ & $63.54 \pm 1.13^{* *}$ & $43.55 \pm 1.05$ & $38.19 \pm 0.49$ \\
\hline ASAT & $22 \pm 2.82$ & $45.5 \pm 6.65^{* *}$ & $28.75 \pm 3.59^{++}$ & $23 \pm 1.02^{++}$ \\
\hline ALAT & $13 \pm 1.41$ & $22.25 \pm 2.75^{* *}$ & $15.5 \pm 2.38^{++}$ & $13.66 \pm 2.08^{++}$ \\
\hline LDH & $692 \pm 38.38$ & $1312.5 \pm 32.63^{* *}$ & $846.25 \pm 58.56^{++}$ & $723.33 \pm 67.71^{++}$ \\
& & & & \\
\hline
\end{tabular}




\section{Captions of figures:}

Figure 1. TBARS (nmol/mg protein) levels and activities of SOD (I.U./mg protein), GPX(I.U./mg protein) and CAT(I.U./mg protein) in liver after 33 days of treatment in controls (C), Cyclophosphamide-treated rats (CP), Cyclophosphamide-treated rats with Marrubium vulgare extract (CPM) and M. vulgare treated rats (M). Values are the mean of 6 measurements $\pm \mathrm{SD} . * * p \leq 0.01$ compared with control group $(\mathrm{C}) .++p \leq 0.01$ compared with treated group $(\mathrm{CP})$.

Figure 2. Scavenging activity of $M$. vulgare extract (at final concentration ranging from 100 to $400 \mu \mathrm{g} / \mathrm{ml}$ ) on the DPPH radical. Each value is repeated in 3 separate assays $\pm \mathrm{SD}$. RSA: Radical scavenging activity.

Figure 3. Reducing power of $M$. vulgare and the synthetic antioxidant ascorbic acid, at different concentrations.

Figure 4. HPLC profile of phenolic acids $(\lambda=280 \mathrm{~nm})$ from $M$. vulgare aqueous extract. Peaks (1) Gallic Acid, (2) Catechic Acid, (3) Caffeic Acid, (4) Epicatechic Acid, (5) Vanillic Acid, (6) Coummarin Acid and 32 unknown compounds. The HPLC analyses were performed using a varian Prostar HPLC equipped with a reverse phase C-18 column (Varian, $150 \mathrm{~mm} \times$ $4.6 \mathrm{~mm}$, particle size $5 \mu \mathrm{m})$. The mobile phase consisted of water: acetic acid (98:2 v/v) (A) and water: acetonitrile: acetic acid (58:40:2 v/v) (B). The elution gradient used was: 0-80\% B for $55 \mathrm{~min}, 80-100 \% \mathrm{~B}$ for $15 \mathrm{~min}$ and $100-0 \% \mathrm{~B}$ for $5 \mathrm{~min}$. The flow rate was $0.9 \mathrm{ml} / \mathrm{min}$ and the injection volume was $20 \mu 1$.

Figure 5. HPLC profile of flavonoids $(\lambda=360 \mathrm{~nm})$ from $M$. vulgare aqueous extract. Peaks (1) Rutin, (2) Quercetin, (3) Kaempferol and 33 unknown compounds. The HPLC analyses were performed using a varian Prostar HPLC equipped with a reverse phase C-18 column (Varian, $150 \mathrm{~mm} \times 4.6 \mathrm{~mm}$, particle size $5 \mu \mathrm{m}$ ). The mobile phase consisted of water: acetic acid (98:2 v/v) (A) and water: acetonitrile: acetic acid (58:40:2 v/v) (B). The elution gradient 
used was: $0-80 \%$ B for $55 \mathrm{~min}, 80-100 \%$ B for 15 min and $100-0 \%$ B for 5 min. The flow rate was $0.9 \mathrm{ml} / \mathrm{min}$ and the injection volume was $20 \mu \mathrm{l}$. 


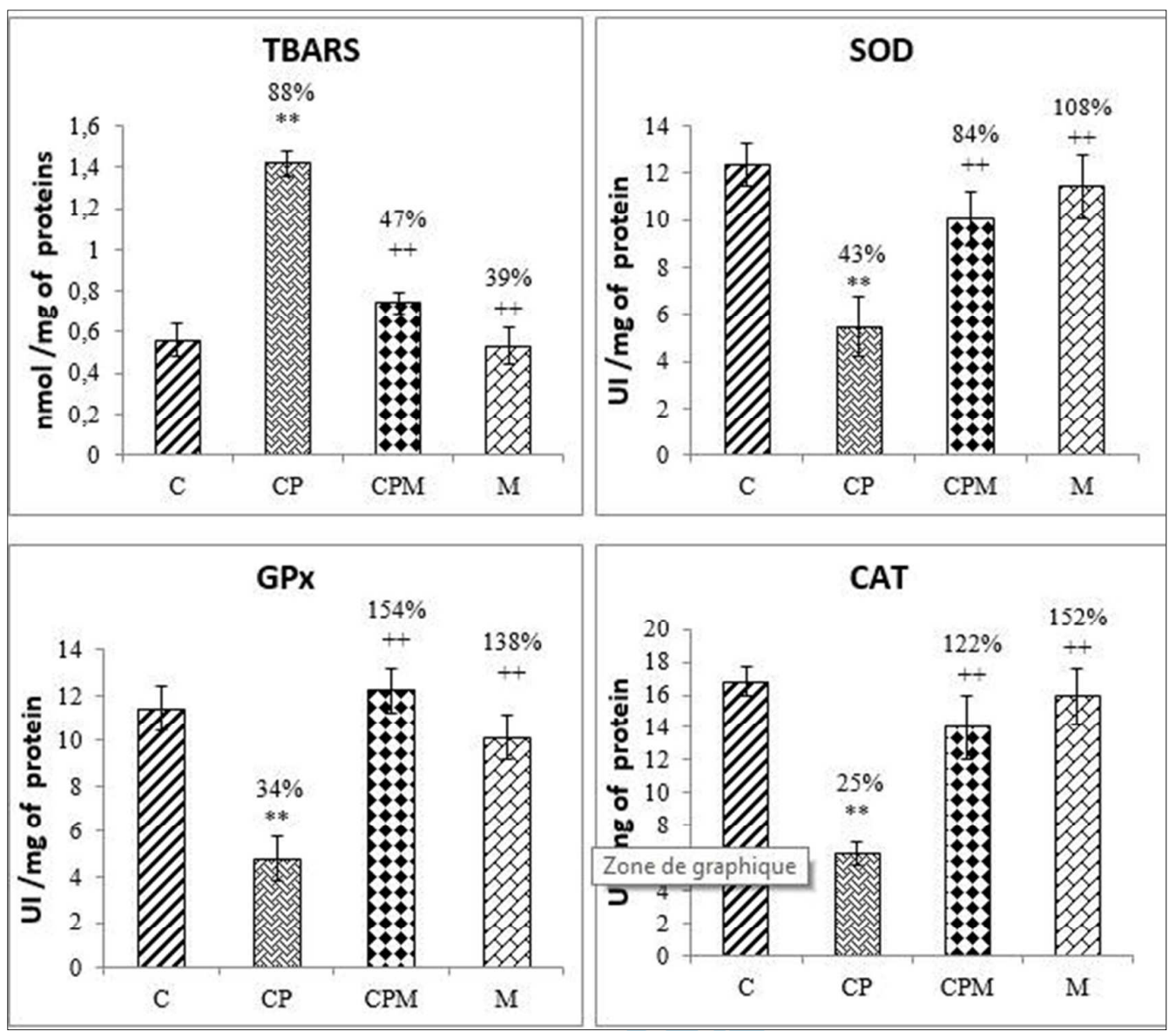

https://mc06.manuscriptcentral.com/cjpp-pubs 


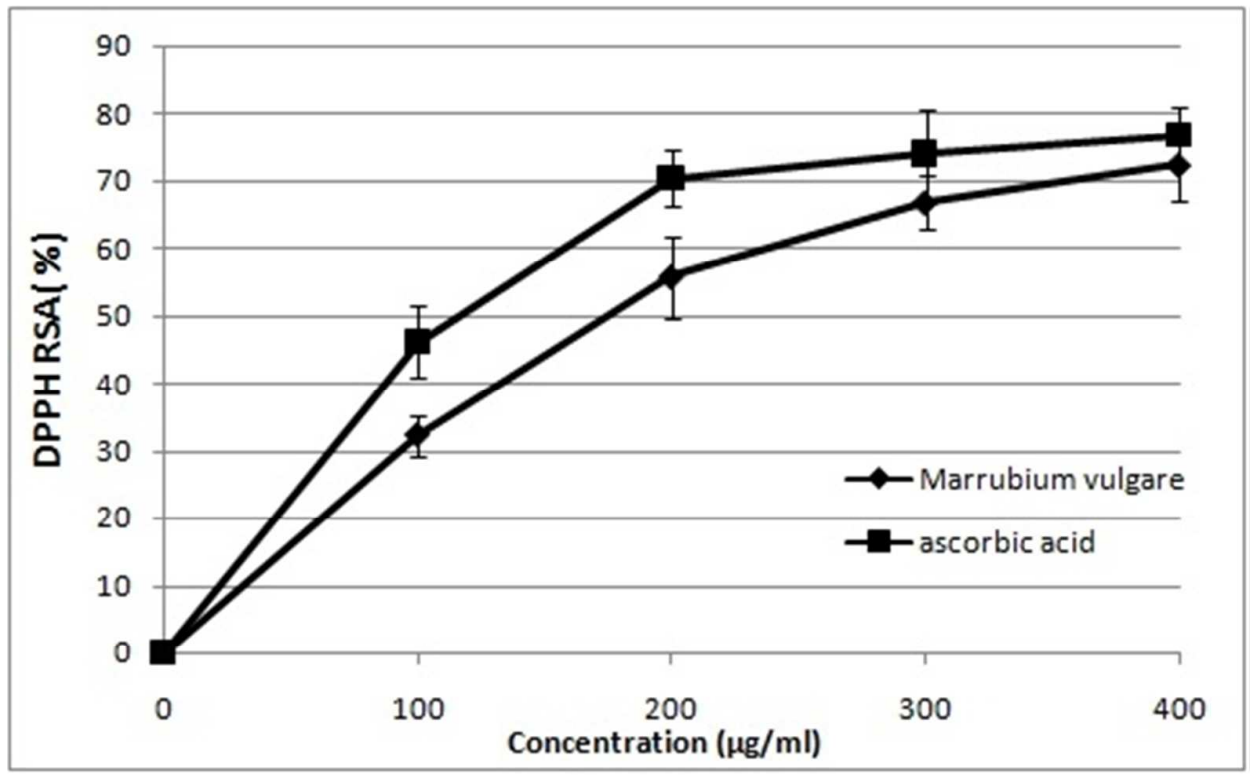




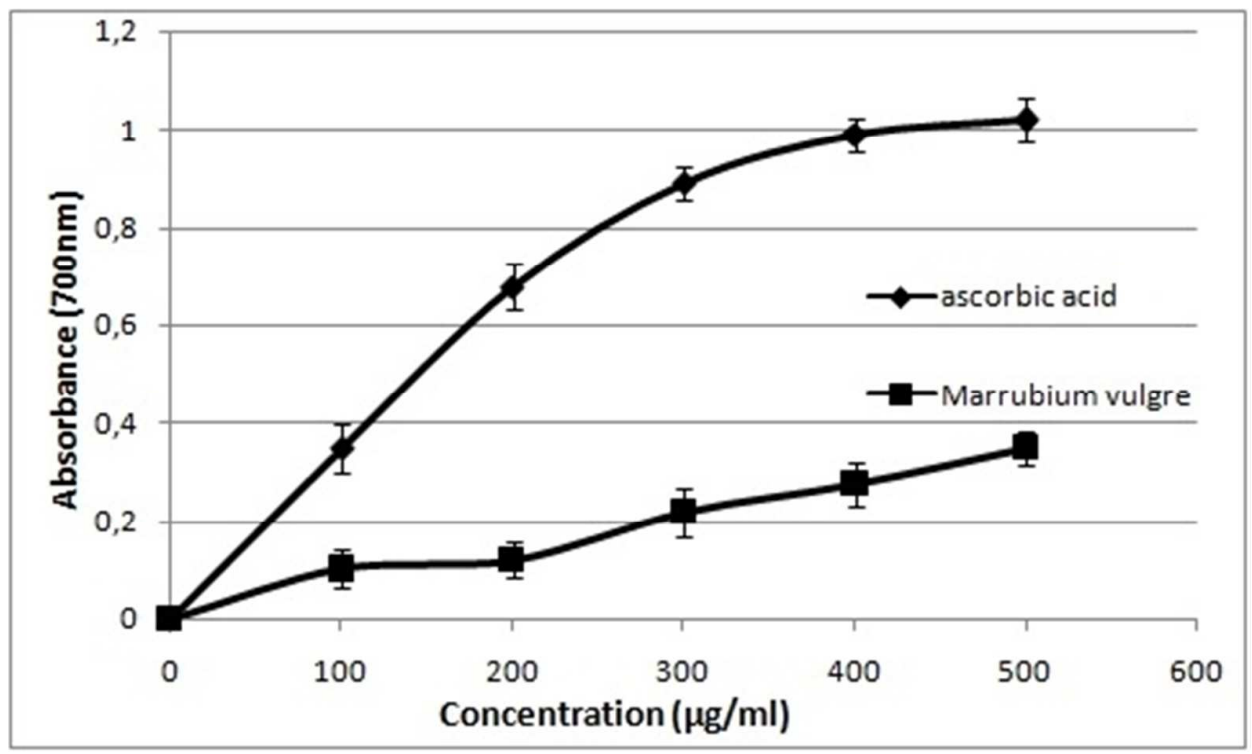

https://mc06.manuscriptcentral.com/cjpp-pubs 


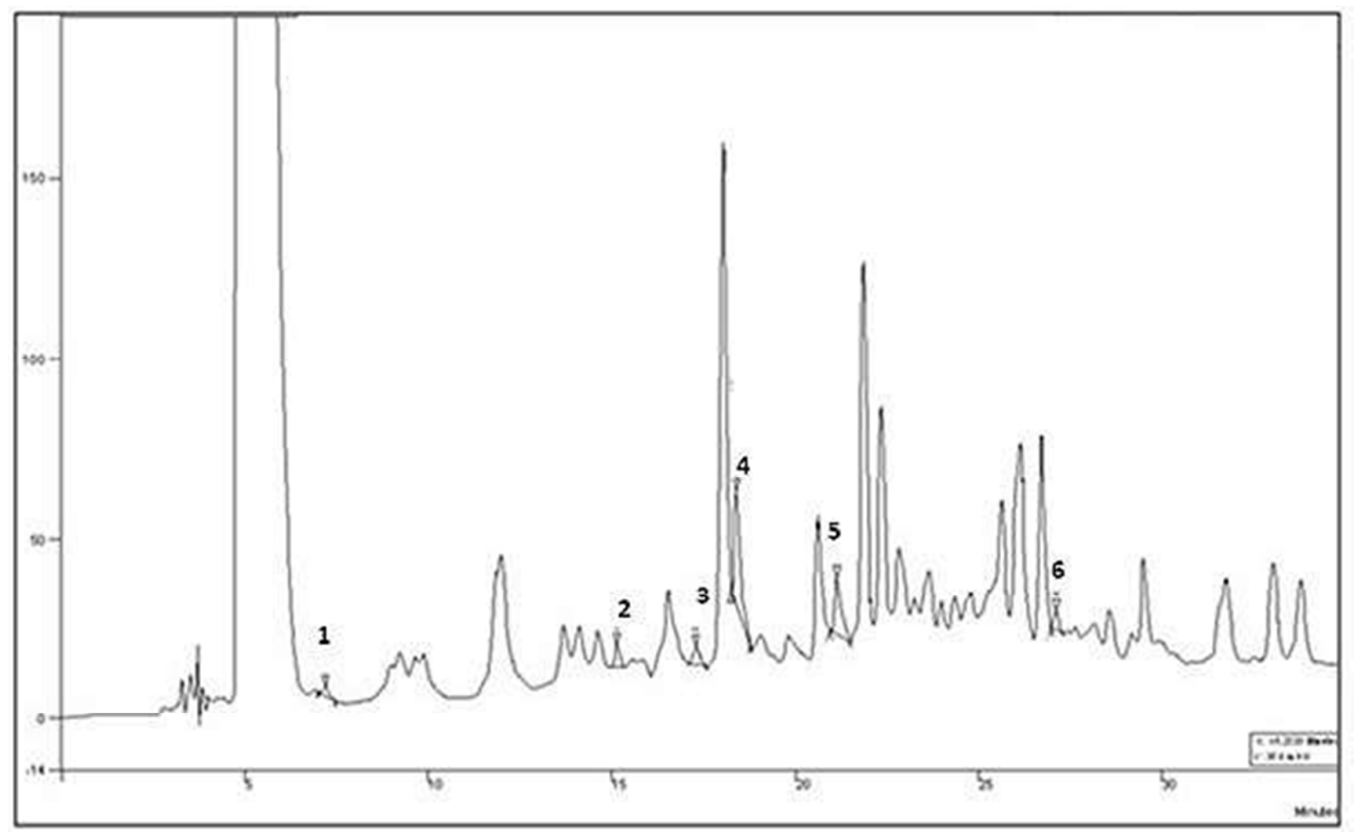

https://mc06.manuscriptcentral.com/cjpp-pubs 


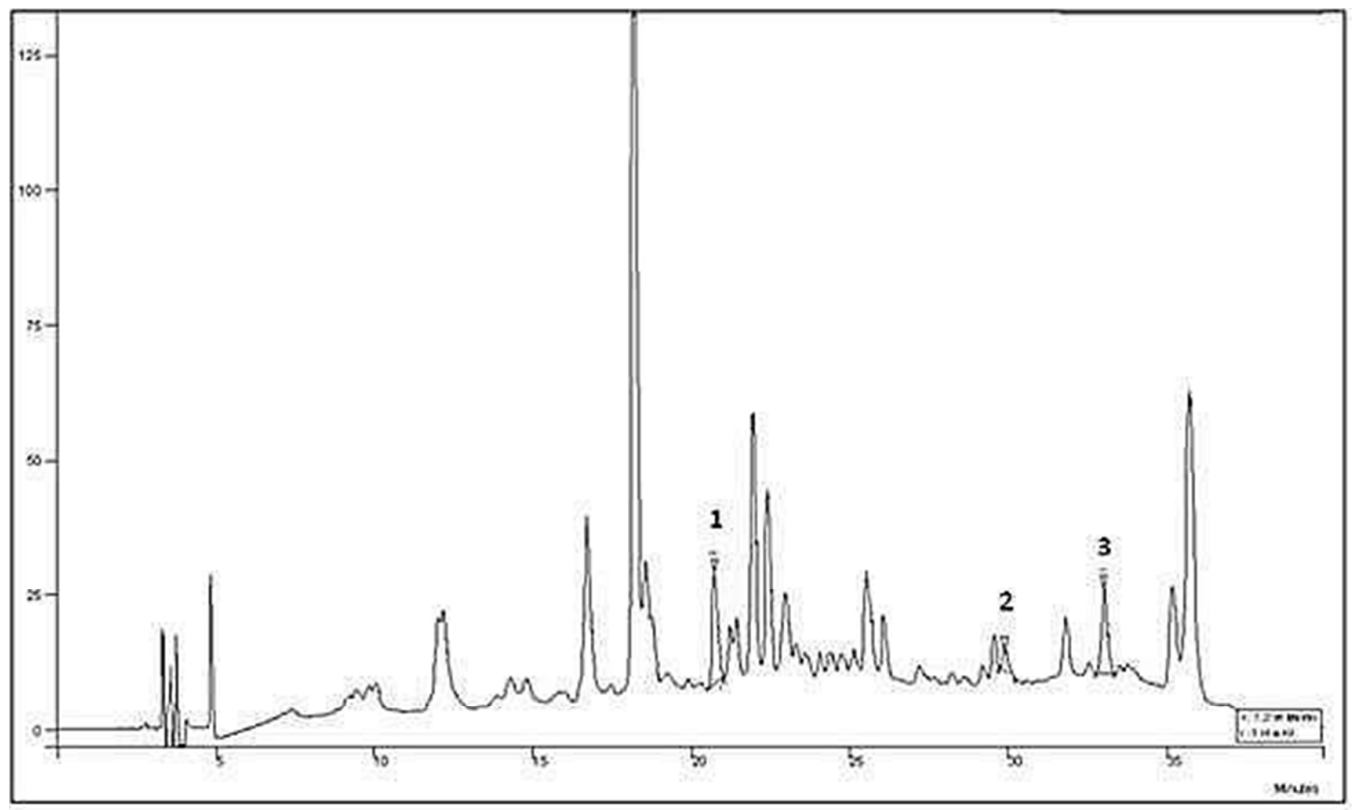

https://mc06.manuscriptcentral.com/cjpp-pubs 
